\title{
Learning and Caring in Communities of Practice: Using Relationships and Collec- tive Learning to Improve Primary Care for Patients with Multimorbidity
}

\author{
Hassan Soubbi, MD, PbD ${ }^{1}$ \\ Elizabeth A. Bayliss, MD, MSPH ${ }^{2}$ \\ Martin Fortin, MD, MSc, CMFC \\ Catberine Hudon, MD, CMFC \\ Marjan van den Akker, $\mathrm{PhD}^{3}$ \\ Robert Thivierge, $M D^{4}$ \\ Nancy Posel, RN, MEd ${ }^{5}$ \\ David Fleiszer, $M D^{5}$ \\ 'Family Medicine Unit, University of Sher- \\ brooke, Chicoutimi, Quebec, Canada \\ ${ }^{2}$ Kaiser Permanente, Denver, Colorado \\ ${ }^{3}$ University of Maastricht, Maastricht, \\ The Netherlands \\ ${ }^{4}$ University of Montreal, Montreal, \\ Quebec, Canada \\ ${ }^{5}$ Faculty of Medicine, McGill University, \\ Montreal, Quebec, Canada
}

Conflicts of interest: none reported

\section{CORRESPONDING AUTHOR}

Hassan Soubhi, MD, PhD

University of Sherbrooke

Family Medicine Unit

305 St-Vallier

Chicoutimi

Quebec, Canada G7H 5H6

hassan.soubhi@usherbrooke.ca

\begin{abstract}
We introduce a primary care practice model for caring for patients with multimorbidity. Primary care for these patients requires flexibility and ongoing coordination, and it often must be tailored to individual circumstances. Such complex and flexible care could be accomplished within communities of practice, whose participants are willing to learn from their shared practice, further each other's goals, share their stories of success and failure, and promote the continued evolution of collective learning. Primary care in these communities would be conceived as a complex adaptive process in which the participants use an iterative approach to care improvement that integrates what they learn and do collectively over time. Clinicians in these communities would define common goals, cocreate care plans, and engage in reflective case-based learning. As community members manage their knowledge, gain insights, and develop new care strategies, they can improve care for patients with multiple conditions. Using a mix of methods, future research should explore the conditions that are necessary for collective learning within communities of clinicians who care for patients with multimorbidity and who develop new knowledge in practice. By understanding these conditions, we can foster the development of collective learning and improve primary care for these patients.
\end{abstract}

Ann Fam Med 2010;8:170-177. doi:10.1370/afm.1056.

\section{INTRODUCTION}

$\mathrm{D}$ elivering primary care to patients with multiple morbidities is challenging. ${ }^{.}$These patients typically consult multiple clinicians, use multiple medications, and compared with patients with a single chronic illness, have higher psychological distress, longer hospital stays, increased use of emergency facilities, and higher rates of mortality. ${ }^{2-21}$ Clinicians who care for them face competing demands, complexities of polypharmacy, difficulties in applying practice guidelines, and increased potential for errors. ${ }^{22,23}$ Clinicians also face increased diagnostic and treatment challenges as different combinations of conditions can interact in unpredictable ways. ${ }^{24-26}$ These challenges occur in the context of comprehensive primary care that includes preventive care, coordination of specialist care, and consideration of patients' priorities in a longitudinal, mutually trusting relationship. ${ }^{26,27}$

These challenges are only partially addressed by accurate disease-specific data and clinical guidelines: the former cannot guide comprehensive decision making that acknowledges patients' preferences and life context, while the latter are often irrelevant for patients with multimorbidity. ${ }^{28}$ Our guiding premise in this article is that caring for these patients is often a 
knowledge-intensive activity which requires amplification of existing professional know-how and insights into coordinating complex assessments and continuous interprofessional care that often goes beyond biomedical needs. We propose a practice model based on (1) the importance of relationships among clinicians in delivering effective patient-centered care, and (2) the flexibility gained in an environment of constant reassessment and case-based learning. In this model, primary care professionals form communities of practice in which they define common goals, cocreate care plans, and engage in reflective case-based learning and practice. ${ }^{29}$ To discuss the application of this model in primary care, we will (1) introduce the model, (2) present relevant theoretical and empirical evidence, (3) propose design strategies for its implementation, (4) contrast its features with other models currently in use, and (5) discuss implications for future research and primary care practice redesign.

\section{COMMUNITIES OF PRACTICE: AN ITERATIVE APPROACH TO CARE IMPROVEMENT}

Suppose that you are a primary care physician caring for a panel of 2,000 patients of whom 30\% suffer from multimorbidity. When you face a challenging clinical problem, you turn to a specific group of colleagues who share your interest in the care of complex patients. These colleagues do not necessarily share your practice, but are only a telephone call away, and you have known them for years. You can count on their help as they understand the issues you face and will explore new ideas with you. You regularly discuss the latest developments in chronic care and each other's practice challenges. You meet either in person or through regular teleconferences to discuss complex cases and develop interprofessional care plans. Your group has a coordinator who organizes your care plans, professional approaches, and discussions into electronic case formats (e-cases) that can be circulated among group members, archived for medical students' learning, and adapted for patient use. ${ }^{30}$ You also have a librarian or information specialist ${ }^{31}$ privy to the group discussions who can synthesize information from the literature to inform reflection and decision making within your group. ${ }^{32-35}$

This kind of scenario and the learning community that emerges from it form the basis of what Wenger calls a Community of Practice: "a group of people who share a concern, a set of problems, or a passion about a topic, and who deepen their knowledge and expertise by interacting on an ongoing basis." ${ }^{136}$ Members of such communities develop a shared repertoire of experiences, stories, tools, and ways of addressing recurring problems that constitute the collective knowledge and memory of the group (Figure 1). ${ }^{36}$

Cultivated among primary care professionals, these communities would provide a social context in which clinicians share clinical cases, listen, reflect, and receive feedback on processes of care for complex patients. ${ }^{37-40}$ Through ongoing conversations, community members would make sense of their experiences and manage their knowledge by sharing their concerns, validating their clinical practices with each other, and developing new care strategies. With time, the accumulation of experiences would increase not only the group's explicit knowledge (written documents, standardized care plans), but also their tacit knowledge or practical know-how that emerges through reflective practice and the collection and sharing of story narratives among professionals. ${ }^{40-42}$ These narratives can include opinions, success and failure stories, solutions to problems, and feedback about tactics and methods. When shared among different users, these narratives can stimulate further validation and learning. ${ }^{42,43}$ In this sense, the community becomes a self-organizing and self-renewing knowledge management system through which clinicians can improve practice outcomes. ${ }^{36,44,45}$

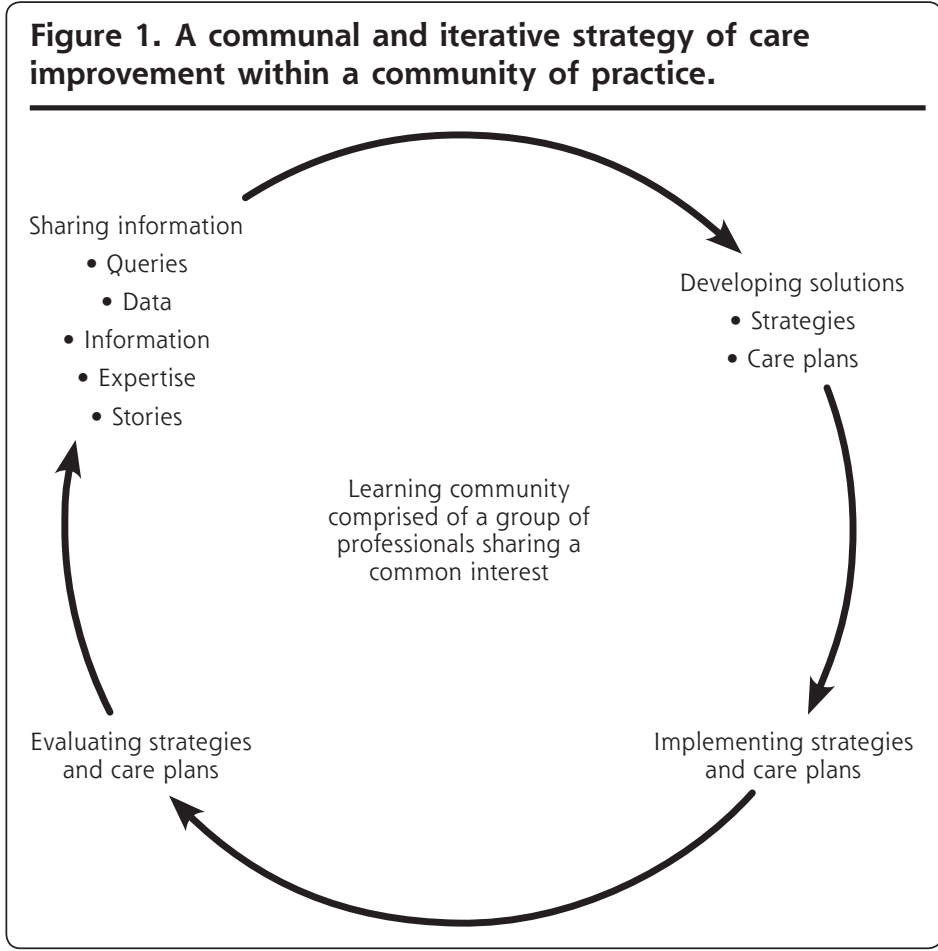

ANNALS OF FAMILY MEDICINE + WWW.ANNFAMMED.ORG + VOL. 8, NO. 2 + MARCH/APRIL 2010 


\section{EMPIRICAL EVIDENCE AND THEORY LINKING CARE PROCESS AND OUTCOMES TO RELATIONSHIPS AND ORGANIZATIONAL LEARNING}

Overall, research suggests that fostering cohesive relationships, teamwork, reflective practice, and organizational learning can with time improve primary care process, outcomes, and clinicians' adaptability. ${ }^{36,46-49}$ Investigations into relationship-centered care emphasize the importance of clinicians' reflective relationships with patients and with each other in supporting satisfying work environments, providing high-quality care, attaining goals, and achieving superior organizational performance. ${ }^{50,51}$ In primary care practices, collaborative culture and greater team cohesion have been associated with improved care access and continuity, better control of diabetes and hyperlipidemia, and increased patient satisfaction. ${ }^{52}$ Improved primary care team effectiveness has also been related to strong leadership, clear goals, selection of skilled and motivated team members, and regular feedback on team's progress. ${ }^{53,54}$

The organizational context of professional practice can also affect care process and outcomes. Several strands of organizational theory conceive of health care organizations as learning systems. ${ }^{36,37,55-58}$ Learning organizations focus on collective learning: acquiring the knowledge and skills necessary for participants to work together to achieve a common task. Learning organizations foster open communication and trust among participants, encourage measured risk, and recognize tacit knowledge as an important source of learning. ${ }^{36,59}$

Preliminary evidence suggests that collective learning can improve collaboration, job satisfaction, employee retention, organizational efficiency, innovation, and customer satisfaction. ${ }^{44,48}$ Collective learning among physicians has been linked to long-term small-group learning in which adult learners use their tacit knowledge-their personal, social, and professional experiences-in the learning process. ${ }^{60}$ Journal clubs and Balint groups are 2 examples in which the use of narratives as learning tools can support the creation of collegial networks, increased self-efficacy, and practice change. ${ }^{60,61}$ An ethnographic study suggests that primary care clinicians rarely access and use explicit evidence from research directly; rather, they rely on "mindlines," defined as collectively reinforced, internalized, tacit guidelines. Mindlines are informed mainly by brief reading, personal experience, interactions with peers, opinion leaders, pharmaceutical representatives, patients, and other sources of tacit knowledge. ${ }^{62}$ In the study, mindlines were iteratively negotiated through informal interactions in fluid communities of practice, resulting in socially constructed "knowledge in practice." ${ }^{112}$
Another strand of organizational theory conceives of primary care practices as complex adaptive systems. These systems are defined as a collection "of individual agents that have the freedom to act in ways that are not always predictable and whose actions are interconnected in such a way that the action of one part changes the context for other agents." ${ }^{163-65}$ Implied is the creation of environments that enhance relationships and provide safe venues for people to voice their ideas and try out small changes that encourage innovation. Data from a 5 -year group-randomized clinical trial using a process of reflective adaptation among care participants indicate that primary care practices can become more reflective and learn from diverse perspectives of the participants. ${ }^{66}$ Mindfulness, facilitative leadership, high-quality relationships, sense making, and feedback in reciprocal interactions increased capacity for collective problem solving, as well as personalized approaches to practice change, all of which support improvement and sustainable delivery of preventive services. ${ }^{67-70}$

\section{DESIGN STRATEGIES FOR COMMUNITIES OF PRACTICE IN PRIMARY CARE}

A community of practice fosters a social context for learning among clinicians who face a common challenge and who collaborate over an extended period to share ideas, nurture relationships, and develop solutions and innovations based on what they learn and do collectively. ${ }^{42,43}$ Although what the participants learn and do cannot be predicted, the context of their practice can be designed with strategies that support diverse participants and enhance collective learning. ${ }^{40,55}$ Two of these strategies have a basis in human ecology: designing for community, and designing for emergent learning and practice. ${ }^{40}$ The first harnesses the potential of relationships; the second focuses on collective learning over time.

\section{Designing for Community}

Designing for community implies that primary care professionals cultivate cohesive relationships through regular contacts, definition of common goals, and recognition of shared skills. ${ }^{36,40,66}$ Such relationships evolve best from small groups who build trust and cohesiveness by identifying their joint interests in patients' care and regular discussion of cases. ${ }^{62}$ These initial communities may then expand to include other members. ${ }^{36,42}$ The composition of a community would be guided by the type of knowledge required to accomplish tasks. Thus communities that focus on the care of patients with multimorbidity might consist of physicians in conjunction with a nurse care coordina- 
tor and other professionals (eg, home care manager, pharmacist) who can contribute strategic perspectives to alleviate care fragmentation. Communities can also cross organizational boundaries to include professionals outside primary care practice.

\section{Designing for Emergent Learning and Practice}

Clinical practice is an evolutionary process in which only effective solutions can thrive under the constraints of cost, efficiency, and other human and organizational factors. ${ }^{63,71-73}$ The content of what community members learn results from their ongoing conversations and interactions with their environments. In this evolutionary process, successful solutions are likely to emerge as members adopt the best solutions through imitation of successful members or through an informed process of learning, experimentation, and continual trial of new and varied solutions. ${ }^{73}$ To design for emergent learning means to provide an adaptive context that supports this kind of learning.

Two components of the social context of a community of practice are essential for an effective design: the relationships among members and the various products they develop and share-assessment tools, care plans, e-cases, reminders, flowcharts, follow-up sheets, etc. ${ }^{55}$ In a sense, these artifacts help create order out of freefloating brainpower of the participants; they give form to the group's experience and provide a basis for continual learning and experimentation. ${ }^{55,74}$ For example, in our preceding scenario, the community uses patients' clinical cases to recruit and align the skills and expertise of multiple professionals. ${ }^{29}$ When systematized, such cases and the practice experience that derives from them are reified into interactive Web-based versions, or e-cases, to support active participation in a virtual environment and promote learning within interprofessional teams. ${ }^{30}$ Figure 2 illustrates how an e-case could be developed and used by community members.
With the assistance of a community coordinator (eg, nurse practitioner), the community uses the e-case as a tool to facilitate reflective practice, help develop a common language among the participants, and encourage active participation by the patient and family. When relevant, an information specialist can help members access the literature to identify gaps in knowledge, overlaps and redundancies in care strategies, and specific roles for community members. These collaborative processes facilitate the transition from uniprofessional care plans into interprofessional care plans and foster an iterative learning process that combines structure with renewed improvisations in the face of uncertainty, uniqueness, and conflicting values. ${ }^{30,40,43,49,55,58,63,75-77}$ Given the potential for group case-based learning, reflective practice sessions could be filmed for further review and improvements, as well as a basis for student learning.

\section{ALTERNATIVE MODELS OF COMPLEX CARE DELIVERY}

Alternative models of primary care delivery for patients with multimorbidity have been proposed, most notably the Guided Care Model (GCM), an expanded case management model for elderly patients based on innovations from the Chronic Care Model (CCM). ${ }^{78-81}$ Our model is similar to the GCM in that it may include a nurse practitioner as coordinator and use the e-case as a case management tool. It differs, however, from the GCM in its emphasis on knowledge management, case-based learning, and the informal ties and shared motivation that bind community members together.

Our model also expands on the CCM to detail possible contents of the "prepared proactive practice team" and the relationship of this team with the "informed, activated patient." 80,82 As they facilitate knowledge management, communities of practice can improve on

\section{Figure 2. Meeting the challenge of interprofessional care through case-based reflective learning in communities of practice.}

\begin{tabular}{|c|c|c|}
\hline \multirow{6}{*}{$\begin{array}{l}\text { Initial Evaluation of Clinical Case } \\
\text { During the Visit } \\
\text { Physician and/or community coordi- } \\
\text { nator define care goals and priori- } \\
\text { ties in concert with the patient } \\
\text { Coordinator create working list of } \\
\text { colleagues and professionals to } \\
\text { be involved in care } \\
\text { Inclusion of initial uniprofessional } \\
\text { assessments and care plan in } \\
\text { e-case to generate a blueprint } \\
\text { of interprofessional care plan }\end{array}$} & \multirow{6}{*}{$\begin{array}{l}\text { Group Discussion and Reflec- } \\
\text { tive Learning } \\
\text { Review of care plan to identify } \\
\text { gaps in information and evi- } \\
\text { dence-based knowledge as } \\
\text { well as redundancies } \\
\text { Formalize plan including defin- } \\
\text { ing expected processes, data } \\
\text { collection, and outcomes } \\
\text { Assign roles and responsibilities } \\
\text { Share plan with patient }\end{array}$} & Follow-Up and Evaluation \\
\hline & & $\begin{array}{l}\text { Measure outcomes and assess } \\
\text { efficacy }\end{array}$ \\
\hline & & sional progress \\
\hline & & Archive e-case and care plan for \\
\hline & & and education \\
\hline & & \\
\hline
\end{tabular}


CCM systems of decision support and clinical information. Their productive interactions with complex patients would result not only from improved coordination and information technology, but also from improved development, harvesting, and use of both explicit and tacit knowledge.

Communities of practice also differ from traditional practice teams. Learners in these communities form naturally occurring clinical groups that are defined by knowledge rather than task. These groups exist not because of an institutional mandate but because participation has value to its members. ${ }^{36}$ Such groups are likely to persist longer than teams formed for specific tasks. ${ }^{36}$ In the traditional practice team, members may not know each other, and physicians may not have time for team development. ${ }^{83}$ Communities of practice integrate teamwork into the group process and may mitigate these difficulties. They tend to be selforganized, self-motivated, and self-renewing precisely because their members agree of their own accord to participate in an activity with a common purpose and value for group members and patients. ${ }^{84}$ As Hildreth and Kimble state it, "members of a community of practice have more in common with a troupe of altruistic volunteers than a band of paid employees." ${ }^{15}$ Learning in this context is less about absorbing information than becoming part of a community; what holds members together are a common sense of purpose and accountability and a need to know what each other knows. ${ }^{85,86}$

Finally, communities of practice have similarities with clinical microsystems, a quality improvement concept. ${ }^{74,87}$ Clinical microsystems are the small systems (human, technological, financial resources) that form around the patient to provide care for variable periods as patient's needs evolve. ${ }^{74}$ Like communities of practice, clinical microsystems involve understanding what group members do to be able to identify specific areas for improvement. Clinical microsystems also integrate learning and practice through group members' commitment to reflection on work and learning and to continual care design. ${ }^{74}$

Unlike clinical microsystems, however, communities of practice are founded on the premise that learning is about social participation and the human connection of groups of people facing similar challenges - the relationship ties among community members drive the learning. In addition, our model incorporates the use of relevant literature. Whereas improved access to the literature helps integrate external inputs of knowledge (explicit knowledge), the e-case, coupled with regular reflective sessions, helps clarify and integrate internal inputs from participants practical know-how (tacit knowledge). As such, communities of practice represent key relational structures that can contribute to collective learning by bridging the gap between knowing and doing that many health care organizations still experience despite improvements in information technology. ${ }^{88}$

\section{RESEARCH IMPLICATIONS}

The preceding discussion provides theoretical and empirical grounding for the hypothesis that relationships and collective learning within communities of practice can improve primary care for patients with multimorbidity. Future research should explore why and how collective learning in naturally occurring communities of practice varies with time. Primary care, similar to other practice settings, involves situations where effective care strategies continue to be used and ineffective ones are weeded out. This process draws attention to the selection process involved in the collective "sense making," by which knowledge and meanings are negotiated among professionals and subsequently standardized in practice. Investigation of this process would help discover the conditions that are necessary for collective learning to emerge. Appropriate actions would then help foster the development of collective learning in primary care practice.

Research would typically ask such questions as, under what conditions would primary care practitioners cooperate, cultivate communities of practice to solve patients' problems collaboratively, and develop knowledge in practice? Current research suggests that such collective learning occurs through the development of trust and effective communication that enables participants to recognize their interdependencies, share common understandings, and subsequently empower the group to address a range of patient care issues..$^{51,66}$ An alternative hypothesis is that this kind of learning may be linked to effective sharing and use of tacit knowledge that are facilitated by working together over time. ${ }^{86}$ Studies on the evolution of cooperation among people who pursue their self-interest suggest that the foundation of cooperation is less about trust, than the durability of the relationship. ${ }^{73}$ In primary care, team tenure-defined as the number of years that physicians in a primary care site had worked with one anotherand shared responsibility for a panel of patients have been associated with improved cancer screening and diabetes management. Team tenure has also been associated with patient satisfaction. ${ }^{83,89}$

Investigating these learning processes will likely require a mix of qualitative and quantitative methods..$^{90}$ Longitudinal approaches would help account for the complex dynamics of ongoing human relationships and knowledge exchange. Detailed observations may explore the ways in which clinicians derive and use 
their knowledge in practice. For example, investigations could examine how primary care physicians develop mindlines and how they test them to eliminate harmful ones and standardize others into routine practice. Studying multiple and diversified primary care settings would also help explore what actually works best in a variegated environment to better understand which kind of mindlines are likely to flourish for which kind of patients with multimorbidity. Repeated observations would be useful to track cumulative learning and specific outcomes for particular profiles of multimorbidity. Further, experimental evidence should also be sought for improved care processes and patient outcomes by comparing communities of practice with usual practice teams, and by investigating the added value of an information specialist in the community in terms of improved decision making and the integration of research-based knowledge into practice.

\section{Implications for Primary Care Practice Redesign}

Redesigning practices based on a community of practice model will require the following components: maximizing the allocation of clinical responsibility based on clinicians' knowledge base and training; senior leaders' supporting community development and iterative change; and inviting experimentation with different payment models. Some of these changes are already underway in many practices, with the increasing incorporation of midlevel clinicians and use of small cycles of practice change. ${ }^{74,83}$

In the proposed model, clinicians at all levels would form communities that address recurring sets of problems together; specifically, clinicians caring for more complex patients may have increased time available to devote to their communities of practice. Because these communities are built on voluntary networks of interest, they should, with support from senior leaders, continually generate value and renewed excitement about collective learning to attract and engage members. ${ }^{36}$ Critical assessment of cost-related outcomes would be particularly important to insure maintenance of redesigned practices. To accelerate collective learning and the evolution of practices, there is a need for appropriate feedback mechanisms related to different payment modalities, eg, pay for performance, payment for complex patients' visits, care-coordination fees, and various incentives for knowledge production and sharing within and between primary care practices.

Caring for patients with multimorbidity invites improvements on existing care models based on ongoing learning and continual evaluation. Self-organized communities of practice illustrate 1 possible model. Clinicians in these communities would improve patient care by building relationships, reflecting on practice, select- ing alternative care strategies, and accomplishing tasks by iterative exploration. ${ }^{29,40,43}$ Testing the added value of communities of practice in primary care remains an empirical issue worth exploring in future research.

To read or post commentaries in response to this article, see it online at http://www.annfammed.org/cgi/content/full/8/2/170.

Key words: Primary health care; multimorbidity; community of practice; interprofessional practice; collective learning; complex adaptive systems

Submitted November 11, 2008; submitted, revised, June 19, 2009; accepted July 23, 2009.

\section{References}

1. Fortin M, Soubhi H, Hudon C, Bayliss EA, van den Akker M. Multimorbidity's many challenges. BMJ. 2007;334(7602):1016-1017.

2. Bodenheimer T. Disease management-promises and pitfalls. N Engl J Med. 1999;340(15):1202-1205.

3. Wright N, Smeeth L, Heath I. Moving beyond single and dua diagnosis in general practice: many patients have multiple morbidities, and their needs have to be addressed. BMJ. 2003;326(7388): 512-514.

4. Zhan C, Sangl J, Bierman AS, et al. Potentially inappropriate medication use in the community-dwelling elderly: findings from the 1996 Medical Expenditure Panel Survey. JAMA. 2001;286(22):2823-2829.

5. Bayliss EA, Steiner JF, Fernald DH, Crane LA, Main DS. Descriptions of barriers to self-care by persons with comorbid chronic diseases. Ann Fam Med. 2003;1(1):15-21.

6. Hansagi H, Olsson M, Sjöberg S, Tomson Y, Göransson S. Frequent use of the hospital emergency department is indicative of high use of other health care services. Ann Emerg Med. 2001;37(6):561-567.

7. Moroney JT, Tseng CL, Paik MC, Mohr JP, Desmond DW. Treatment for the secondary prevention of stroke in older patients: the influence of dementia status. J Am Geriatr Soc. 1999;47(7):824-829.

8. Nutting PA, Goodwin MA, Flocke SA, Zyzanski SJ, Stange KC. Continuity of primary care: to whom does it matter and when? Ann Fam Med. 2003;1(3):149-155.

9. Starfield B, Lemke KW, Bernhardt T, Foldes SS, Forrest CB, Weiner JP. Comorbidity: implications for the importance of primary care in 'case' management. Ann Fam Med. 2003;1(1):8-14.

10. Flocke SA, Frank SH, Wenger DA. Addressing multiple problems in the family practice office visit. J Fam Pract. 2001;50(3):211-216.

11. Fortin M, Bravo G, Hudon C, et al. Relationship between multimorbidity and health-related quality of life of patients in primary care. Qual Life Res. 2006;15(1):83-91

12. Fortin M, Lapointe L, Hudon C, Vanasse A, Ntetu AL, Maltais D. Multimorbidity and quality of life in primary care: a systematic review. Health Qual Life Outcomes. 2004;2:51.

13. Fortin M, Bravo G, Hudon C, Lapointe L, Dubois MF, Almirall J. Psychological distress and multimorbidity in primary care. Ann Fam Med. 2006;4(5):417-422.

14. West DW, Satariano WA, Ragland DR, Hiatt RA. Comorbidity and breast cancer survival: a comparison between black and white women. Ann Epidemiol. 1996;6(5):413-419.

15. Extermann M. Measurement and impact of comorbidity in older cancer patients. Crit Rev Oncol Hematol. 2000;35(3):181-200.

16. Incalzi RA, Capparella O, Gemma A, et al. The interaction between age and comorbidity contributes to predicting the mortality of geriatric patients in the acute-care hospital. J Intern Med. $1997 ; 242(4): 291-298$ 
17. Poses RM, McClish DK, Smith WR, Bekes C, Scott WE. Prediction of survival of critically ill patients by admission comorbidity. J Clin Epidemiol. 1996;49(7):743-747.

18. Librero J, Peiró S, Ordiñana R. Chronic comorbidity and outcomes of hospital care: length of stay, mortality, and readmission at 30 and 365 days. J Clin Epidemiol. 1999;52(3):171-179.

19. Rochon PA, Katz JN, Morrow LA, et al. Comorbid illness is associated with survival and length of hospital stay in patients with chronic disability. A prospective comparison of three comorbidity indices. Med Care. 1996;34(11):1093-1101.

20. Brennan TA, Leape LL, Laird NM, et al. Incidence of adverse events and negligence in hospitalized patients. Results of the Harvard Medical Practice Study I. N Engl J Med. 1991;324(6):370-376.

21. Wilson RM, Runciman WB, Gibberd RW, Harrison BT, Hamilton JD. The Quality in Australian Health Care Study. Med J Aust. 1995;163(9):458-471.

22. Weingart SN, Wilson RM, Gibberd RW, Harrison B. Epidemiology of medical error. BMJ. 2000;320(7237):774-777.

23. Bar-Yam Y. System Care: Multiscale Analysis of Medical Errors - Eliminating Errors and Improving Organizational Capabilities. NECSI Technical Report 2004-09-01. New England Complex Systems Institute; 2004.

24. Rolland JS. Toward a psychosocial typology of chronic and lifethreatening illness. Fam Syst Med. 1984;2(3):245-262.

25. Katerndahl DA. Is your practice really that predictable? Nonlinearity principles in family medicine. J Fam Pract. 2005;54(11):970-977.

26. Starfield B, Shi L, Macinko J. Contribution of primary care to health systems and health. Milbank Q. 2005;83(3):457-502.

27. World Health Organization. World Health Report 2008-Primary Health Care: Now More Than Ever. Geneva: WHO; 2008.

28. Van Spall HGC, Toren A, Kiss A, Fowler RA. Eligibility criteria of randomized controlled trials published in high-impact general medical journals: a systematic sampling review. JAMA. 2007;297(11): 1233-1240.

29. Fraser SW, Greenhalgh T. Coping with complexity: educating for capability. BMJ. 2001;323(7316):799-803

30. Posel N, Fleiszer D, Wiseman J, et al. Using electronic cases to teach healthcare professionals and students about interprofessionalism. J Interprof Care. 2008;22(1):111-114.

31. Davidoff F, Florance V. The informationist: a new health profession? [editorial]. Ann Intern Med. 2000;132(12):996-998.

32. Lamb G. A decade of clinical librarianship. Clin Lib Q. 1982;1(1):2-4.

33. Scura G, Davidoff F. Case-related use of the medical literature. Clinical librarian services for improving patient care. JAMA. 1981;245(1): 50-52.

34. Marshall JC. The impact of the hospital library on clinical decision making: the Rochester study. Bull Med Libr Assoc. 1992;80(2): 169-178.

35. Veenstra RJ. Clinical medical librarian impact on patient care: a one-year analysis. Bull Med Libr Assoc. 1992;80(1):19-22.

36. Wenger E, McDermott R, Snyder WM. Cultivating Communities of Practice: A Guide to Managing Knowledge. Boston, MA: Harvard Business School Press; 2002.

37. Bohmer RMJ, Edmondson AC. Organizational learning in health care. Health Forum J. 2001;44(2):32-35.

38. Parboosingh JT. Physician communities of practice: where learning and practice are inseparable. J Contin Educ Health Prof. 2002;22(4): 230-236.

39. Schon D. Teaching artistry through reflection-in-action. In: Tsoukas $\mathrm{H}$, ed. New Thinking in Organizational Behaviour: From Social Engineering to Reflective Action. Oxford, England: Butterworth-Heinemann Ltd; 1994:1-22
40. Soubhi H. Toward an ecosystemic approach to chronic care design and practice in primary care. Ann Fam Med. 2007;5(3):263-269.

41. Lockyer J, Gondocz ST, Thivierge RL. Knowledge translation: the role and place of practice reflection. J Contin Educ Health Prof. 2004 24(1):50-56.

42. Donaldson A, Lank E, Maher J. Making the invisible visible: how a voluntary organization is learning from its work with groups and communities. J Change Manag. 2005;5(2):191-206.

43. Soubhi H, Colet NR, Gilbert JH, et al. Interprofessional learning in the trenches: fostering collective capability. J Interprof Care. 2009;23(1):52-57.

44. Hildreth P, Kimble C. Knowledge Networks: Innovation Through Communities of Practice. London, UK: Idea Group Publishing; 2004.

45. St-Onge $H$, Wallace D. Leveraging Communities of Practice For Strategic Advantage. Boston, MA: Butterworth-Heinemann; 2003.

46. Aiken LH, Smith HL, Lake ET. Lower Medicare mortality among a set of hospitals known for good nursing care. Med Care. 1994; 32(8):771-787.

47. Shortell SM, Jones RH, Rademaker AW, et al. Assessing the impact of total quality management and organizational culture on multiple outcomes of care for coronary artery bypass graft surgery patients. Med Care. 2000;38(2):207-217.

48. Senge P. The Fifth Discipline: The Art \& Practice of the Learning Organization. New York, NY: Currency Doubleday; 1990.

49. Schön D. The Reflective Practitioner. How Professionals Think in Action London: Temple Smith; 1983

50. Safran DG, Miller W, Beckman H. Organizational dimensions of relationship-centered care. Theory, evidence, and practice. J Gen Intern Med. 2006;21(Suppl 1):S9-S15.

51. Hoff T. The Power of Frontline Workers in Transforming Organizations. New York, NY: The Upstate New York Veterans Health Administration: IBM Center for Healthcare Management; 2003.

52. Cohen JE, Hann M, Hacker J. Universities and tobacco money. BMJ. 2001;323(7303):1-2.

53. Ross F, Rink E, Furne A. Integration or pragmatic coalition? An evaluation of nursing teams in primary care. J Interprof Care. 2000;14(3):259-267.

54. Borrill CS, Carletta J, Carter AJ, et a. The Effectiveness of Health Care Teams in the National Health Service. Birmingham, UK: Ashton Centre for Health Service Organization Research; 2001.

55. Wenger E. Communities of Practice: Learning, Meaning, and Identity. New York, NY: Cambridge University Press; 1998.

56. Miller DR. The architecture of simplicity. Acad Manage Rev. 1993; 18(1):116-138.

57. Smith EA. Communities of competence: new resources in the workplace. J Workplace Learn. 2005;17(1/2):7-23.

58. Smith R. Towards a knowledge based health service. BMJ. 1994; 309(6949):217-218

59. Gee JP. Communities of practice in the new capitalism. J Learn Sci. 2000;9(4):515-523.

60. Pereles L, Lockyer J, Fidler H. Permanent small groups: group dynamics, learning, and change. J Contin Educ Health Prof. 2002; 22(4):205-213.

61. Rabin S, Maoz B, Elata-Alster G. Doctors' narratives in Balint groups. Br J Med Psychol. 1999;72(Pt 1):121-125.

62. Gabbay J, le May A. Evidence based guidelines or collectively constructed "mindlines?" Ethnographic study of knowledge management in primary care. BMJ. 2004;329(7473):1013.

63. Plsek PE, Greenhalgh T. Complexity science: The challenge of complexity in health care. BMJ. 2001;323(7313):625-628.

64. Wilson T, Holt T, Greenhalgh T. Complexity science: complexity and clinical care. BMJ. 2001;323(7314):685-688. 
65. Plsek PE, Wilson T. Complexity, leadership, and management in healthcare organisations. BMJ. 2001;323(7315):746-749.

66. Stroebel CK, McDaniel RRJ, Crabtree B, Miller W, Nutting PA, Stange KC. How complexity science can inform a reflective process for improvement in primary care practices. Jt Comm J Qual Saf. 2005;31:438-446.

67. Miller WL, McDaniel RRJ Jr, Crabtree BF, Stange KC. Practice jazz: understanding variation in family practices using complexity science. J Fam Pract. 2001;50(10):872-878.

68. Scott J, Tallia A, Crosson JC, et al. Social network analysis as an analytic tool for interaction patterns in primary care practices. Ann Fam Med. 2005;3(5):443-448.

69. Goodwin MA, Zyzanski SJ, Zronek S, et al; The Study to Enhance Prevention by Understanding Practice (STEP-UP). A clinical trial of tailored office systems for preventive service delivery. Am J Prev Med. 2001;21(1):20-28.

70. Cohen D, McDaniel RRJ Jr, Crabtree BF, et al. A practice change model for quality improvement in primary care practice. $J$ Healthc Manag. 2004;49(3):155-168, discussion 169-170.

71. Bar-Yam Y. Making Things Work. Solving Complex Problems in a Complex World. Brookline, MA: NESCSI, Knowlege Press; 2004.

72. Axelrod R, Cohen MD. Harnessing Complexity. Organizational Implications of a Scientific Frontier. New York, NY: Basic Books; 2000.

73. Axelrod R. The Evolution of Cooperation. New York, NY: Basic Books; 2006.

74. Nelson EC, Batalden PB, Godfrey MM. Quality By Design: A Microsystems Approach. San Francisco, CA: Jossey-Bass; 2007.

75. Shaughnessy AF, Slawson DC, Becker L. Clinical jazz: harmonizing clinical experience and evidence-based medicine. J Fam Pract. 1998;47(6):425-428.

76. Kolb DA. Experiential Learning: Experience as the Source of Learning and Development. Englewood Cliffs, NJ: Prentice-Hall; 1984.

77. Haidet P. Jazz and the 'art' of medicine: improvisation in the medical encounter. Ann Fam Med. 2007;5(2):164-169.
78. Boult C, Karm L, Groves C. Improving chronic care: the guided care model. Permanente J. 2008;12(1):50-54

79. Wagner EH, Davis C, Schaefer J, Von Korff M, Austin B. A survey of leading chronic disease management programs: are they consistent with the literature? Manag Care Q. 1999;7(3):56-66.

80. Wagner EH, Austin BT, Von Korff M. Organizing care for patients with chronic illness. Milbank Q. 1996;74(4):511-544.

81. Dorr DA, Wilcox A, Burns L, Brunker CP, Narus SP, Clayton PD. Implementing a multidisease chronic care model in primary care using people and technology. Dis Manag. 2006;9(1):1-15.

82. Von Korff M, Gruman J, Schaefer J, Curry SJ, Wagner EH. Collaborative management of chronic illness. Ann Intern Med. 1997;127(12): 1097-1102.

83. Bodenheimer T, Grumbach K. Improving Primary Care. Strategies and Tools for a Better Practice. New York, NY: McGraw-Hill Companies, Inc; 2007.

84. Lave J, Wenger E. Situated Learning. Legitimate Peripheral Participation. Cambridge: University of Cambridge Press; 1991.

85. Kimble C, Hildreth P. Communities of Practice: Going One Step Too Far? Proceedings 9e colloque de I'AIM. Evry, France; 2004.

86. Brown S, Gray S. The people are the company. Fast Company. 1995; 1. http://www.fastcompany.com/magazine/01/people.html?page $=$ 0\%2CO.

87. Committee on Quality of Health Care in America. Institute of Medicine. Crossing the Quality Chasm: A New Health System for the 21st Century. Washington, DC: National Academy Press; 2001.

88. McGlynn EA, Asch SM, Adams J, et al. The quality of health care delivered to adults in the United States. N Engl J Med. 2003;348 (26):2635-2645.

89. Parkerton PH, Smith DG, Straley HL. Primary care practice coordination versus physician continuity. Fam Med. 2004;36(1):15-21.

90. Kernick D, Stead J, Dixon M. Moving the research agenda to where it matters. BMJ. 1999;319(7204):206-207. 